\title{
Six Potential Superior Durian Plants Resulted by Cross Breeding of $D$. zibethinus and D. Kutejensis From East Kalimantan, Indonesia: Initial Identification
}

\author{
Odit Ferry Kurniadinata1*, Song Wenpei² ${ }^{2}$ Achmad Zaini1 ${ }^{1}$, Rusdiansyah¹ \\ ${ }^{1}$ The Agriculture Faculty, Mulawarman University, Samarinda, East Kalimantan Province, Indonesia \\ ${ }^{2}$ College of Horticulture and Landscape Architecture, Zhongkai University of Agriculture and Engineering, Guangzhou, China. \\ *Corresponding author: odit.ferry@faperta.unmul.ac.id
}

\section{ARTICLE HISTORY \\ Received : : 11 August 2019 \\ Revised : 23 September 2019 \\ Accepted : 2 October 2019}

\section{KEYWORDS}

Tropical rain forest, Local fruit Crossbreeding, germplasm Preservation

\begin{abstract}
Kalimantan Island is rich in genetic resources and species diversity of Durio spp. Of the 27 durian species in the world, 18 species are found in Borneo. The large number of Durio species that grow in Kalimantan illustrates that this area is the most important distribution center for durian relatives. Two of the best-known edible durians in East Kalimantan are Durian (Duriozibethinus) and Lai (Durio kutejensis). However, as a plant with a cross-pollination mechanism, there are many results of natural crosses between the two. The study aimed to identify Durian x Lai plants in Loa Kulu, Kutai Kertanegara, East Kalimantan Province, Indonesia as the superior local fruit crops potentially agribusiness industry. This research was carried out by collecting data and information about the morphological characteristics of the plants and fruits from $D$. Zibenthinus $\mathrm{x}$ D. Kutejensis. The results of the study successfully identified 6 potentially superior plants that are believed to be the result of a cross between D. Zibenthinus x D. kutenjensis. The 6 potential superior plants were found to have different morphological characters. This is the initial identification and being a basis of the next research phase, which is to identify the morphology of trees, flowers, and fruit to obtain new cultivars crossing D.zibenthinus and D. Kutejensis which have superior potential as superior commodities from East Kalimantan.
\end{abstract}

This is an open access article under the CC-BY-SA license.

\section{INTRODUCTION}

Kalimantan is the largest island in Indonesia, with a high level of biodiversity in the world. Kalimantan, especially East Kalimantan, is a place of mega biodiversity with humid tropical forest climate conditions (Samir et al., 2014; Ercisli and Sagbas, 2017). Humid tropical climate is a climate with humidity above $90 \%$, high rainfall (more than 150 mm.year-1), annual temperature above $180 \mathrm{oC}$, and the difference between the rainy season and the dry season is not very clear (Poepenoe, 1974). One of the rich diversity that exists is the presence of various types of tropical fruits, most of which are endemic to East Kalimantan. Indonesia is one of the eight centers of plant genetic diversity in the world, especially for tropical fruits such as durian (Bioversity International, 2007; Brown, 1997). At present, it is recorded that of around 27 species of Durio worldwide, 18 of them grow in Kalimantan, 11 are in Malaya, and seven are in Sumatra (Milow et al., 2014). The high number of Durio species that grow in Kalimantan illustrates that this area is the most important distribution center for durian relatives. In addition to being rich in Durian diversity, Indonesia is also rich in the diversity of sources of germplasm from Durio. For example, the durian that is commonly consumed besides Durio zibethinus, namely Lai (Durio kutejensis), as well as the results of a natural cross between the two. In Indonesia, there are quite a lot of durian cultivars that differ from one another in taste, aroma, and color of the flesh. Even durian seeds can be found without seeds.

The great diversity of species and sources of germplasmDurio spp. in Indonesia is a very important basic capital for breeders (Poerwanto, 2003; Ryugo, 1988; Chakravarty et al., 2016; Handayani, 2017). From the results of plant breeding, it is expected that superior seeds will be obtained both in quality and fruit production. Indonesia, especially Kalimantan island, is the center of the distribution of Durio. This rich diversity of species and germplasm has not been used optimally. Therefore, plant breeding in durian relatives (Durio spp.) 
in Indonesia needs to be done to produce superior cultivars/seeds (Ministry of Agriculture Republic of Indonesia, 2011). This can be done, among others, by collecting data and information about the rich diversity of species and sources of germplasm Durio spp. in Indonesia (Belgis et al., 2015). The next step is to choose the types of sources of germplasm that have more value. With the availability of diversity in germplasm types or sources, the desired superior cultivars/seeds will be assembled. To be able to determine the type of plants to be planted on a piece of land, it must be known the characteristics of these plant types, especially in relation to climate, soil, and growth velocity factors (Marschner, 1995; Bernier et al., 2000; Sundari 2015).Plants with cross-pollination mechanism as well as the genus Durio spp. derived from natural crosses in nature is very difficult to obtain with potentially superior character (Chakravarty et al. 2016). Therefore it is important to do a series of morphological identification activities and documentation of potential superior commodities in East Kalimantan. Kutai Kertanegara Regency has many durians, lai, and lai-durian trees that have been traditionally and conventionally planted for a long time, and this has caused many interesting modifications of the durian plant character to be studied and scientifically identified.

This study aimed to find, identify, and initially characterize lai-durian plants in Loa Kulu, Kutai Kertanegara District, East Kalimantan, as potentially superior local fruit plants.

\section{MATERIALS AND METHODS}

This research was conducted using a descriptive method of exploration. Sampling method with purposive sampling, by tracing the primary data and secondary data from the informer, either directly from the key person(s) and library data. Observations were carried out on productive crops, having produced more than three times, and could be a parent plant. Live interviews with Durian tree owner farmers, and then made characterization of durian plant demonstration. The experiment was conducted in Loa Kulu, Kutai Kertanegara, East Kalimantan, Indonesia, Agronomy Laboratory, The Faculty of Agriculture, Mulawarman University, Samarinda, East Kalimantan Province, Indonesia, from January to June 2019. The Research was conducted used the method of IPGRI (2007) to morphological characteristics, which include the fruits shape, fruit color, flesh aroma, flesh taste, fruit spine shape, leaf upper color, leaf lower color, and Crown Shape. Identification was done by the survey method and IndeptIntervew to the owner of plants and farmers, as well as related stakeholders to explore the potential of Lai-Durian fruit crops.

\section{RESULTS AND DISCUSSION}

Kalimantan Island, which covers the Sabah and Sarawak (Malaysia), Brunei, and Kalimantan (Indonesia) region, is one of the origin and diversity of durian relatives. The durian (Durio spp.) tree in Kalimantan still grows wild in the primary forests as well as mixed forests, and only a small portion of the inhabitants have been planted in gardens. The type D. Durio Murray (Durian) can be found on the islands of Borneo, Java, Sumatra, Sulawesi, and Maluku. This durian Habitat is in primary and secondary forest and can grow on various types of soil.

This durian is also widely cultivated by people in Kalimantan, including in East Kalimantan (Uji, 2005). It was reported that in Kalimantan there were 22 species of durian. In general, a cross between D. Zhibenthinus and D. Kutejensis in East Kalimantan is referred to as the Lai Durian plant. However, the characters that appear vary, in plants of the cross D. Zhibenthinus and D. Kutejensis tend to be grouped in the lai plant, given some special features that appear like the color of flowers, fruit, and aroma of fruit. Lai durian has leaves that are quite large, larger than the leaves of durian but smaller than the Lai leaves, as well as the size of the flowers.

The flower is pink, while the durian flowers are white and red. The fruit is gently scented with a sweet flavor and dry texture. The shape of the durian fruit is varied but generally relatively oval with the color of the flesh varies from yellow to orange. As it is Lai, the fruit Lai durian needs to be cured for 4-5 days before maturity, so that the shelf life of fruit after the harvest becomes longer is about 7-10 days.

\subsection{The diversity of the morphology of Durian (Durio spp.)}

Observations were carried out at every phase of the growth and production of the Lai x Durian fruit crop, which grows in the jealousy of Loa Kulu, Kabupaten Kutai Kertanegara, East Kalimantan. Based on the observation of the morphological character of the durian accession in Loa Kulu jealousy, Kutai Kertanegara Regency, East Kalimantan, showed that there was diversity in the morphological characteristics of trees, leaves, flowers, fruits, and seeds. Based on the heading form, there were six kinds of durian accession forms. There were six cultivars of lai-durian which were identified as plants having the superiority and potential of the local, each named based on number: Lai Durian No. 1, Lai Durian No. 2, Lai Durian No. 3, Lai Durian No. 4, Lai Durian No. 5, and Lai Durian No. 6.

\section{a. D. Zibenthinus x D. Kutejensis No. 1}

The tree was up to $10 \mathrm{~m}$ tall. Fruits green to yellow, globose, ovoid or ellipsoid, Fruits had an elliptic shape with conical spine shape, a clear segment line, mild flesh aroma, ripe on the tree, and did not fall upon maturity, Sweet flesh taste. Leaves alternate, elliptical, or lanceolate-elliptical. This fruit was one of the fruits chosen as one of the crosses of D. Zibenthinus $x$ D. Kutejensis potentially superior to Loa Kulu and named as Lai Durian Loa Kulu No. 1. 


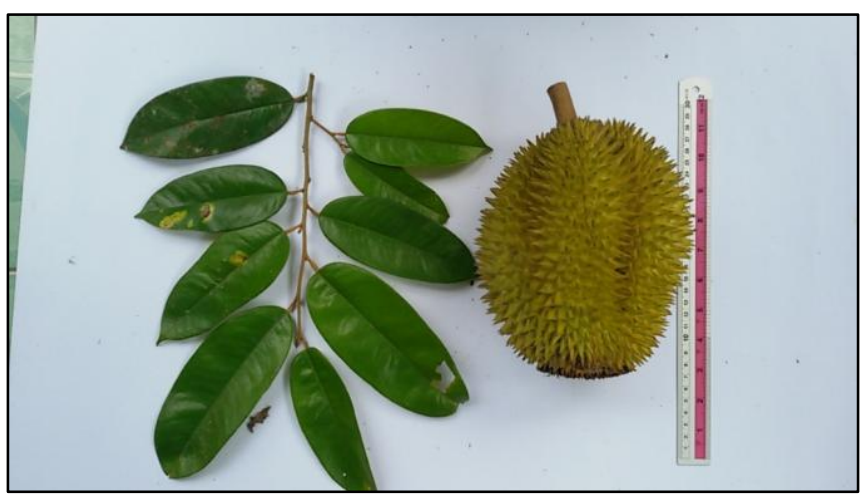

Figure 1. Fruit and Leaf of Lai Durian Loa Kulu No. 1

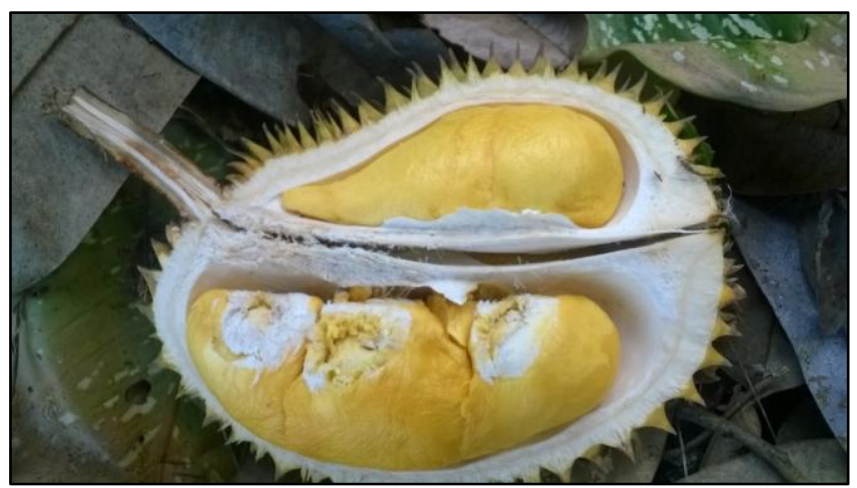

Figure 2. Aryl of Lai Durian Loa Kulu No. 1

\section{b. D. Zibenthinus $x$ D. Kutejensis No. 2}

The tree was up to $10 \mathrm{~m}$ tall. Fruits color was greenish-yellow, oblong with concave spine shape, had a clear segment line, mild flesh aroma, ripe on the tree and fallen upon maturity, sweet flesh taste, with small seeds, Aryl arranged stacked with each other. Leaves alternate, elliptical, or lanceolate-elliptical. This fruit was one of the fruits chosen as one of the crosses of D. Zibenthinus $x \mathrm{D}$. Kutejensis potentially superior to Loa Kulu and named as Lai Durian Loa Kulu No. 2.
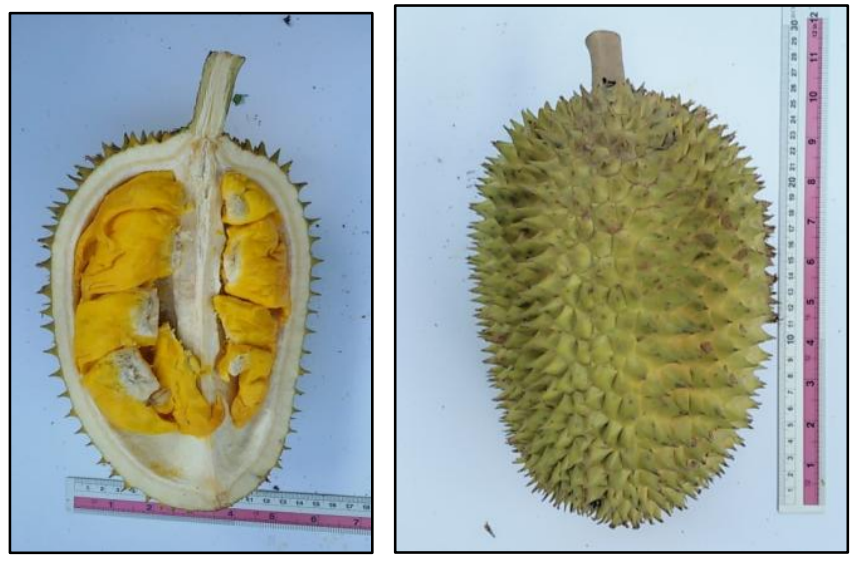

Figure 3. Fruit and Aryl of Lai Durian Loa Kulu No. 2

\section{c. D. Zibenthinus x D. Kutejensis No. 3}

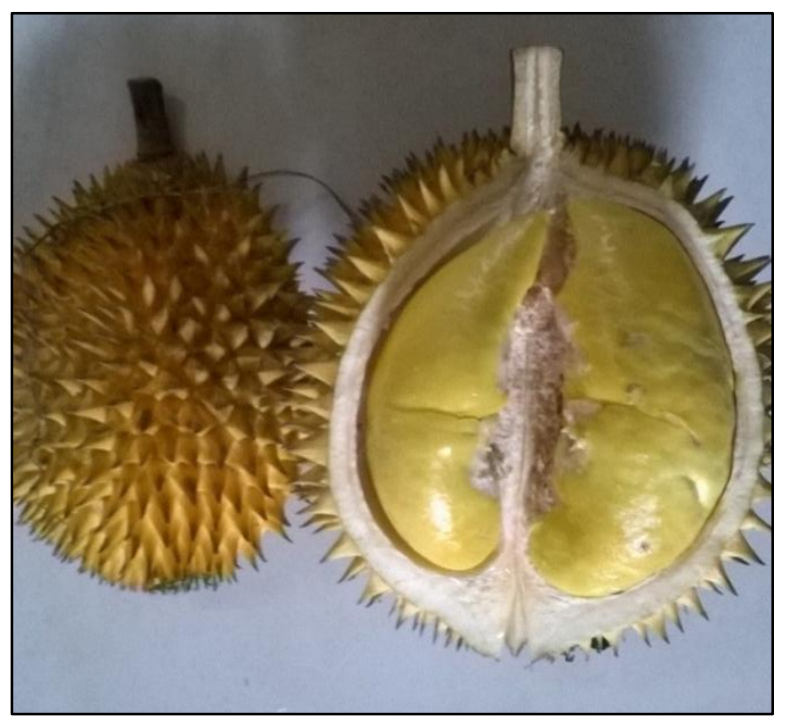

Figure 4. Fruit and aryl of Lai Durian No. 3 Loa Kulu

The tree was up to $9 \mathrm{~m}$ tall. Fruits color is orange-yellow, globose with conical spine shape, had a clear segment line, strong aroma, ripe on the tree, and fallen upon maturity, sweet flesh taste with medium seed size. Leaves alternate, elliptical, or lanceolate-elliptical. This fruit was one of the fruits chosen as one of the crosses of D. Zibenthinus $x$ D. Kutejensis potentially superior to Loa Kulu and named as Lai Durian Loa Kulu No. 3.

\section{d. D. Zibenthinus $x$ D. Kutejensis No. 4}

Lai Durian no. 4 Loa Kulu Fruits had an obovoid shape with greenish-yellow color, conical spine shape, a clear segment line, strong flesh aroma, fallen when ripe but not open, soft and dry texture of flesh, medium seeds size. This fruit was one of the fruits chosen as one of the fruits of the crossing of D. Zibenthinus x D. Kutejensis had the potential to be superior to Loa Kulu.

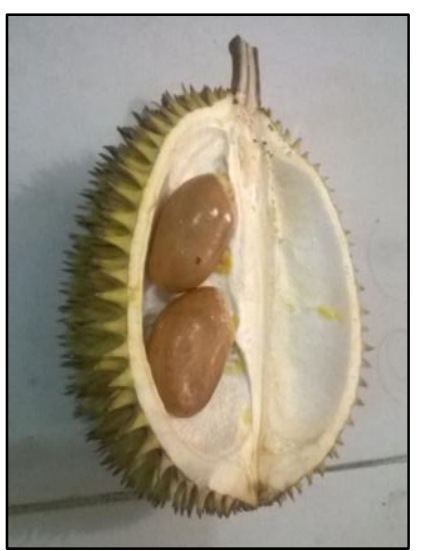

Figure 5. Seed and Aryl of Lai Durian No. 4 Loa Kulu

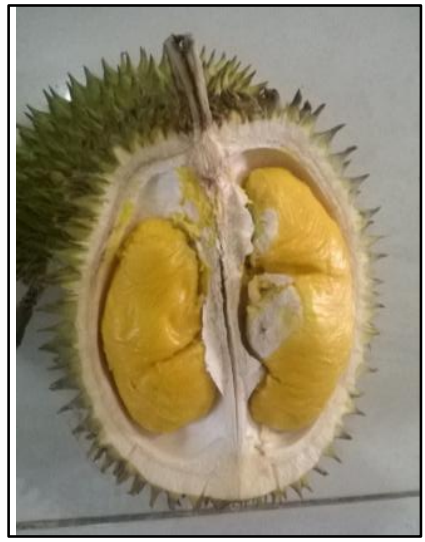




\section{e. D. Zibenthinus $x$ D. KutejensisNo. 5}

The tree was up to $10 \mathrm{~m}$ tall. Fruits color was greenish-yellow, globose with conical spine shape, had a clear segment line, strong flesh aroma, ripe on the tree and fallen upon maturity, and sweet flesh taste leaves alternate, elliptical or elliptic-oblong. This fruit was one of the fruits chosen as one of the crosses of D. Zibenthinus $x$ D. Kutejensis potentially superior to Loa Kulu and named as Lai Durian Loa Kulu No. 5.

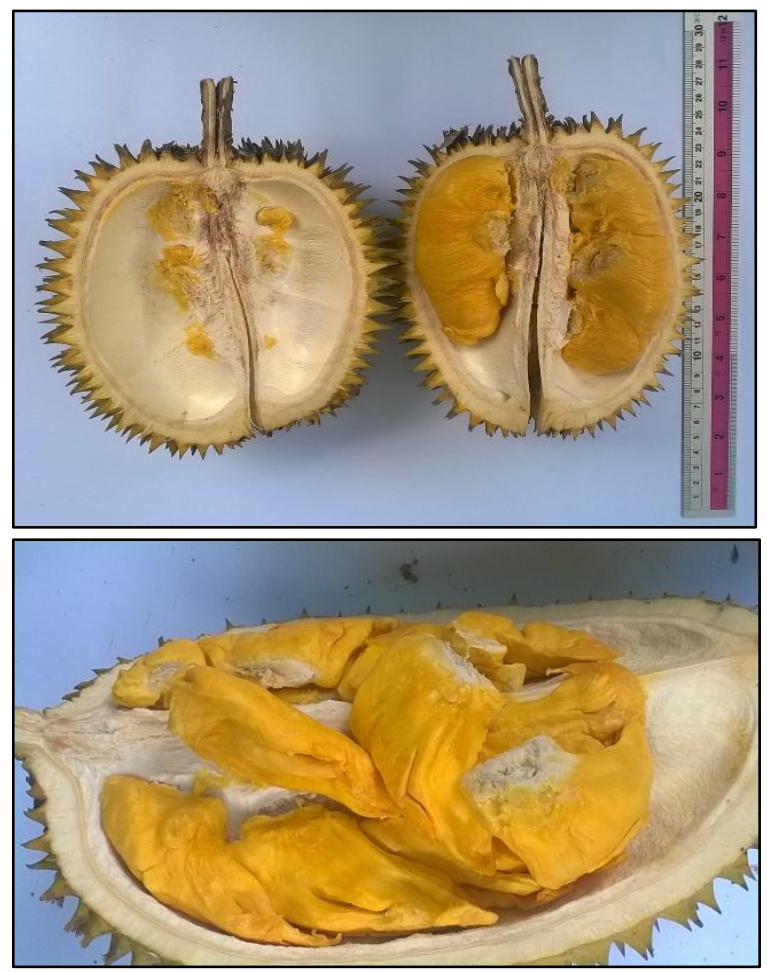

Figure 6. Fruit and Aryl of Lai Durian No. 5 Loa Kulu

\section{f. D. Zibenthinus $x$ D. Kutejensis No. 6}

Table1. Morphological Character of the Six Lai Durians

\begin{tabular}{|c|c|c|c|c|c|c|}
\hline \multirow{2}{*}{ Characters } & \multicolumn{6}{|c|}{ Accession number } \\
\hline & 01 & 02 & 03 & 04 & 05 & 06 \\
\hline Fruits shape & Elliptic & Oblong & Globose & Obovoid & Globose & Obovoid \\
\hline \multirow[t]{2}{*}{ Fruit color } & Greenish Yellow & Greenish & Orange Yellow & Greenish Yellow & Greenish Yellow & Light Greenish Yellow \\
\hline & & Yellow & & & & \\
\hline Fresh aroma & Mild & Mild & Strong & Strong & Strong & moderate \\
\hline Flesh taste & Sweet & Sweet & Sweet & Sweet & Sweet & Sweet \\
\hline Fruit spine shape & Conical & Concave & Conical & Conical & Conical & Conical \\
\hline \multirow[t]{2}{*}{ Leaf upper color } & Green & Dark Green & Dark Green & Dark Green & Dark Green & Dark Green \\
\hline & & Coppery & Coppery & & & \\
\hline Leaf lower color & Coppery Brown & Brown & Brown & Silvery Brown & Coppery Brown & Silvery Brown \\
\hline Crown Shape & Oblong & Irregular & Semi Circular & Semi Circular & Pyramidal & Oblong \\
\hline
\end{tabular}

Lai Durian No. 6 Loa Kulu tree was up to $10 \mathrm{~m}$ tall. Fruits color was greenish-yellow with obovoid fruit shape, had conical spine shape, a clear segment line, moderate aroma, ripe on the tree, and fallen upon maturity, sweet thick flesh, with medium seed size, leaves alternate, elliptical or lanceolate-elliptical. This fruit was one of the fruits chosen as one of the crosses of D. Zibenthinus x D. Kutejensis potentially superior to Loa Kulu and named as Lai Durian Loa Kulu No. 6.

Each plant that had been identified had a different fruit appearance from one to another especially from the parent (D.zibenthinus and D. kutejensin), both in terms of shape, size, color, aroma, taste, the thickness of aryl, aryl color, and several other agronomic characteristics. This became the basis for further research to identify each cultivar with a more specific agronomic and morphological character. 


\section{CONCLUSION}

The six potential superior plants found had different morphological characteristics. Fruits shape, fruit color, fruit odor, aryl taste, fruit spear, leaf size, leaf color, canopy structure. This was the basis of the next research phase, which was to identify the morphology of trees, flowers, and fruit to obtain new cultivars crossing D. zibenthinus and D. Kutejensis, which have superior potential as superior commodities from East Kalimantan.

\section{Acknowledgments}

This project was supported by The Faculty of Agriculture Mulawarman University Research Project 2019.

\section{REFERENCES}

Belgis, M., Wijaya, C.H., Apriyantono, A., Kusbiantoro, B. and Yuliana, N.D. 2015. Physicochemical differences and sensory profiling of six lai (Durio kutejensis) and four durians (Durio zibethinus) cultivars indigenous Indonesia. International Food Research Journal 23(4): 1466-1473.

Bernier, G., J.M.Kinet, R.M. Sachs. 2000. The Physiology of Flowering: volume 1, the initiation of flowers. CRC Press, Inc. Florida.

Bioversity International. 2007. Descriptors For Durian (Durio zibethinus Murr.). Bioversity International. Rome.

Brown, M.J. 1997. Durio-A Bibliographic Review. International Plant Genetic Resources Institute. India.

Chakravarty S, Karma D. Bhutia, C. P. Suresh, Gopal Shukla, and Nazir A. Pala 2016. A review on diversity, conservation, and nutrition of wild edible fruits. Journal of Applied and Natural Science 8 (4): 2346-2353(2016).

Ercisli S. and Sagbas HI,. 2017. Wild Edible Fruits: A Rich Source of Biodiversity. ANADOLU, Journal. of AARI (Aegean Agricultural Research Institute).

Handayani, R. S. (2017). Analisis Keragaman Kualitas Buah Durian Unggulan (Durio zibethinus) Aceh Utara. Jurnal Hortikultura Indonesia, 8(3), 147-154.

Marschner H. 1995. Mineral Nutrition of Higher Plants. 2nd edition. Academic Press. London.

Milow P., SorayyaBibiMalek, Juli Edo, Hean-ChooiOng. 2014. Malaysian Species of Plants with Edible Fruits or Seeds and Their Valuation. International Journal of Fruit Science, 14:1-27.

Ministry of Agriculture Republic of Indonesia, 2011. The Guiding Book to make Description and test the Correctness of Horticulture Plant Varieties, The Decision of Agriculture Ministry, Republic of Indonesia. PP. 129.

Poepenoe, W. 1974. Manual of Tropical and Subtropical Fruits. 2nd book. Hafner Press. New York.

Poerwanto, R. 2003. Teaching Materials for Fruit Cultivation. Module VII. Land Management and Fruit Garden Fertilization. Horticulture Study Program, Faculty of Agriculture. IPB. Bogor

Ryugo K. 1988. Fruit Culture: its Science and Art. John Wiley and Sons, Inc. New York.

Samir C. Debnath, David Percival, and Yaw L. Siow. 2014. Biodiversity and Conservation of Wild Small Fruit Species for a Sustainable Environment. Conference: International Horticultural Congress, At Brisbane, Australia, Volume: Plant Genetic Resources For Climate Change.

Sundari. 2015. Morphological Variation of Local Durian (Durio zibethinusMurr.) on The Ternate Island. The First International Conference on Life Science a Biotechnology, Exploration, And Conservation Of Biodiversity. [Proceeding]. 